\title{
An Ontology about Expertise Management
}

\author{
Hans de Bruin, Gabriëlle Rossing \\ Research Center Expertise and Valorization Management, HZ University of Applied Sciences, Vlissingen, The Netherlands \\ Email: hans.de.bruin@hz.nl
}

How to cite this paper: de Bruin, $H$. and Rossing, G. (2017) An Ontology about Expertise Management. Journal of Computer and Communications, 5, 101-120. http://dx.doi.org/10.4236/jcc.2017.51009

Received: December 15, 2016

Accepted: January 19, 2017

Published: January 22, 2017

Copyright () 2017 by authors and Scientific Research Publishing Inc. This work is licensed under the Creative Commons Attribution International License (CC BY 4.0).

http://creativecommons.org/licenses/by/4.0/

\begin{abstract}
An Expertise Management ontology $\left(\mathrm{EM}_{\text {ont }}\right)$ is presented with which human expertise is captured. $\mathrm{EM}_{\mathrm{ont}}$ aims at describing and collectively finding improvements for complex situations in which people interact with often conflicting worldviews in order to achieve goals, shared or not. $\mathrm{EM}_{\text {ont }}$ is rooted in systems thinking, in particular Soft Systems Methodology, to be able to accommodate stakeholders' worldviews and activities in complex situations. Its purpose is to model human activity systems, which is illustrated with the help of a complex situation. $\mathrm{EM}_{\text {ont }}$ forms the heart of the Expertise Management Methodology (EMM). This methodology can be regarded as a framework to build bodies of knowledge for particular domains systematically. EMM favors a research process of abduction. By studying one or more situations, generalized models are developed that explain the observed phenomenon best. The models are then taken as a starting point to conduct additional studies. This cyclic process is repeated thereby strengthening the models. $\mathrm{EM}_{\text {ont }}$ has been applied in several, diverse domains such as flood protection, health care and community resilience, over a period of more than four years. In our experience, $\mathrm{EM}_{\text {ont }}$ is a stable ontology, well-suited to capture human activities and identify widely supported solutions for complex situations, and has proven its value in practice. $\mathrm{EM}_{\text {ont }}$ has been implemented in Semantic Media Wiki to publish bodies of knowledge on the web.
\end{abstract}

\section{Keywords}

Ontology, Semantic Web, Expertise Management, Soft Systems Methodology

\section{Introduction}

Processes in today's society are of a complex nature. Increasingly we are facing so-called wicked problems in situations in which participants sense improvement is needed but it is unclear how to proceed. A "wicked problem" is a phrase to describe a problem that is difficult or impossible to solve because of incomplete, contradictory, and changing requirements that are often difficult to recog- 
nize. Typically, wicked problems are caused by conflicting worldviews of the participants involved. Domains of wicked problems can easily be identified, and include, for example, health, safety and sustainability.

It is hard to find solutions for wicked problems, because a solution that is acceptable and feasible for one group of people may be unacceptable for another group. Therefore, it is better to consider a wicked problem as a "problematic situation". Systems thinking provides a framework to analyze problematic situations systematically and to find arguably desirable and culturally feasible improvements.

\subsection{Systems Thinking}

A system or situation consists of entities (like stakeholders, organizations, machinery), their beliefs, and relations between the entities. Stakeholders involved in a situation strive for various goals and have different worldviews, which are inspired by their experience and beliefs. In other words, stakeholders have a notional, constructed view of the world, which does not necessarily match reality. Interaction between entities of a situation results in emergent properties that cannot be traced to individual entities: the whole is bigger than the sum of its parts. Systems thinking enables to view the situation as a whole and to understand the context of the situation. According to Churchman [1]: "a systems approach begins when first you see the world through the eyes of another". Understanding the entities, and particularly the worldviews of stakeholders, enables the emergence and development of synergy or desired emergent properties in a situation.

A framework for understanding complex situations low in synergy, i.e. problematic situations including stakeholders with different and sometimes conflicting worldviews, is the Soft Systems Methodology (SSM) [2] [3]. SSM is based on systems thinking. In essence, SSM provides a framework for a "group learning process" or co-creation. Stakeholders are working collectively on improving the problematic situation, first by understanding the entire situation including each other's worldview and preferences, and then to find improvements collectively. Via a process of co-creation stakeholders make use of each other's expertise and experiences to finding sustainable improvements and ways to collaborate. These improvements provide action perspectives that can be of use in other, yet similar situations.

Human activity typically depends on the situation or context it occurs in. It depends on the behavior of other people in the situation, or more generally: human activity depends on entities exhibiting behavior, as well as environmental constraints in the situation. Human activity is assessed with SSM by taking the worldviews of stakeholders into account in the form of human activity systems, which are notional systems that express some purposeful human activity. Human activity is described in SSM as purposeful activity models shaped by the so-called $\mathrm{PQR}$ formula addressing What $(\mathrm{P})$, How $(\mathrm{Q})$, and Why $(\mathrm{R})$ questions. 


\subsection{Expertise Management Methodology}

Expertise Management is defined as utilizing each other's expertise in order to collectively address a problematic situation. Expertise is the special skill or knowledge that you get from experience, training, or study. EMM provides a framework for applying the Expertise Management ontology $\left(\mathrm{EM}_{\text {ont }}\right)$ in order to facilitate co-creation and utilize expertise, both in physical and virtual networks of experts and expertise and from the perspective of Critical Realism. EMM can be applied to systematically build a Body of Knowledge and Skills (BoKS) of a particular knowledge domain. Developing a BoKS requires a structured approach to capture the skills and knowledge (experience) of experts. EMM is centered around the $\mathrm{EM}_{\text {ont }}$ for that purpose, which is discussed extensively in this article alongside the embedding of $\mathrm{EM}_{\text {ont }}$ in EMM.

\subsection{Defining Knowledge}

Knowledge is a concept that is difficult to grasp. It is often defined as justified true belief, that is, $S$ knows that $p$ iff:

- $p$ is true;

- $S$ believes that $p$;

- $S$ is justified in believing that $p$.

There are two problems with using this definition. First, the definition itself is problematic. Gettier showed that there are cases, the so-called Gettier cases, in which the three conditions hold, but these are not sufficient for knowledge [4]. Second, the definition provides no clue how to structure knowledge.

A more practical approach is to use the Data-Information-Knowledge-Wisdom (DIKW) pyramid (Figure 1). There are many explanations for interpreting the layers of the pyramid, see for example [5]. For our purposes, we use the following interpretation:

- Data-Data as signals, symbols or facts;

- Information-Information is inferred from data in the process of answering interrogative questions (e.g., "who", "what”, "where”, "how many", “when”);

- Knowledge-Application of data and information; answers "how" questions, i.e., understanding patterns;

- Wisdom-Understanding principles, learning form past actions.

Besides making the distinction between the aforementioned layers of the

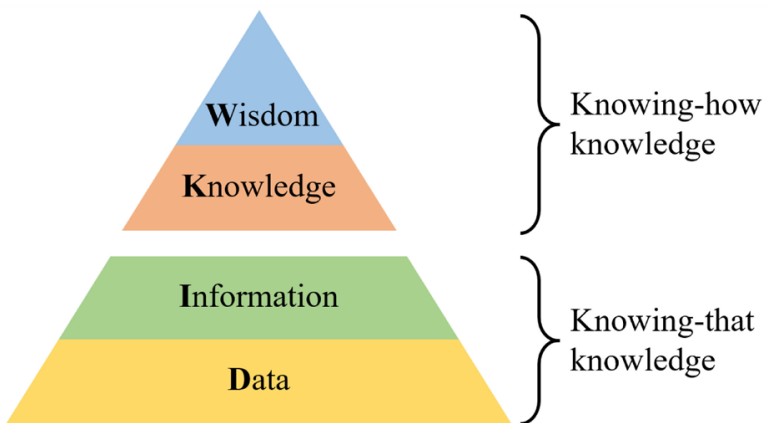

Figure 1. The DIKW pyramid, consisting of knowing-how and knowing-that knowledge. 
DIKW pyramid, it is also useful to distinguish between knowing-that (propositional) and knowing-how (procedural) knowledge. Knowing-how knowledge refers to DI layers of the pyramid, whereas knowing-that knowledge refers to the KW layers.

\subsection{The Memory-Prediction Framework}

In EMM, we are especially interested in the upper, knowing-how part of the DIKW pyramid, but the lower part is not neglected since applying knowing-how knowledge requires propositional, knowing-that knowledge. $\mathrm{EM}_{\text {ont }}$ is the ontology for describing knowing-how knowledge and the way knowledge of several actors can be applied in specific situations to achieve goals collectively. The key idea of $\mathrm{EM}_{\text {ont }}$ is based on the Memory-Prediction Framework (MPF) by Hawkins [6], who has given an account of how the brain, in particular, the neocortex, is structured to produce intelligent behavior. Kurzweil has proposed recently a similar model [7]. Both proposals are a bit speculative in places, however, their proposals are grounded in the seminal work of Mountcastle who discovered the columnar structure of the neocortex [8].

The columnar structures form a hierarchy of temporal patterns. At the lower level of the hierarchy, patterns are activated by the human senses by means of a self-associating pattern recognition process. That is, the stimuli of the senses match the beginning of a pattern and the pattern then predicts the next stimuli. Once a lower level pattern is recognized, it triggers a higher level pattern, which on its turn predicts what is going to happen by activating lower level patterns to anticipate next stimuli or triggers from lower level patterns, and so on. In case stimuli from senses and triggers from patterns do not match a pattern any longer, a pattern is abolished.

The elegance of this model is that a single algorithm explains intelligent behavior. Lessons from the past are coded in patterns. These patterns are used to predict the (nearby) future. When predictions fail, new patterns take over and in this way the neocortex is continuously adapting to changing circumstances.

The pattern hierarchy is not fixed. Newly encountered experiences result in the creation of new patterns and adaptation of the hierarchical pattern structure. In short, we learn to handle in similar situations based on past experiences. The patterns become routines. For example, the routine of driving a car requires patterns that can be applied almost without consciously thinking. In fact, as experience grows, the patterns become more and more complex and are internalized as tacit knowledge [9]. For example, we know how to drive a car, but it is difficult to explain how we do it.

Of course, what we learn from experiences need not necessarily be the right way of doing things. The point is, however, it is our personalized way of doing things. As such, the MPF gives an account for human activity systems. It suggests that human activity is organized hierarchically in terms of patterns, and that these patterns are shaped according to individual experiences, which gives an explanation for differences in worldviews. 


\subsection{Outline of the Article}

This article is organized as follows. First we introduce $\mathrm{EM}_{\text {ont }}$ by example. This is followed by a more formal account of the ontology. Next we discuss EMM and the role of $\mathrm{EM}_{\text {ont }}$ to systematically constructing BoKS. In the section on implementation, we show how the open source platform Semantic MediaWiki is used to implement $\mathrm{EM}_{\text {ont }}$. Finally, we discuss related work, followed by looking back and ahead.

\section{Introducing EMont with the Help of a Case}

Knowing-how knowledge (expertise, behavior and (non-)human activities) and worldviews of people acting in particular situations can be described and assessed with $\mathrm{EM}_{\text {ont }}$. $\mathrm{EM}_{\text {ont }}$ consists of modeling elements, i.e., concepts and relations, which will be introduced shortly with help of the fictitious and simplified situation of people counteracting a flooding disaster.

The ontology is presented with the help of concept maps, a visual notation for relating concepts. As such, a concept map can be regarded as the visual counterpart of the fundamental semantic web proposition: subject $\stackrel{\text { predicate }}{\longrightarrow}$ object .

\subsection{Capturing Activities with the PQR Formula}

Human activity systems, as well as activities of other kinds of actors like machinery, can be modeled with help of the PQR formula. It concisely captures (human) activities executed to deal with particular circumstances which are motivated by the actors' worldview. The formula is pivotal to $\mathrm{EM}_{\text {ont }}$ and originates from the Soft Systems Methodology. Applying the PQR formula touches upon the expertise or knowing-how knowledge of an expert. It shapes a root definition: a statement written in a few sentences capturing the essence of someone's worldview. The PQR formula reads like a sentence: "Do P by a $\mathrm{Q}$ in order to achieve R". The letters $\mathrm{P}, \mathrm{Q}$ and $\mathrm{R}$ do not resemble anything, except for being subsequent letters in the alphabet. A specific meaning, however, is attached to these letters (see Table 1).

The PQR formula applied to the case of counteracting a disaster (see Figure 2) looks like: "You can counteract the disaster ( $\mathrm{P}-$ What?) by, depending on the circumstances, fighting it (Q1-How?) or evacuating (Q2-How?) in order to save you and your relatives' lives ( $\mathrm{R}-$ Why?)".

The $\mathrm{PQR}$ formula is in $\mathrm{EM}_{\text {ont }}$ applied recursively in line with the recursive nature of patterns in the MPF. A How $(\mathrm{Q})$ can be decomposed in more specific or diverse How's (Q's). To continue from the example in Figure 2: the evacuation

Table 1. The meaning of $\mathrm{P}, \mathrm{Q}$ and $\mathrm{R}$ of the PQR formula.

\begin{tabular}{cccc}
\hline PQR & & Meaning \\
\hline $\mathrm{P}$ & What? & Activity & $\begin{array}{r}\text { What activity are we going to do, perform, } \\
\text { execute or what process is going to happen? }\end{array}$ \\
$\mathrm{Q}$ & How? & Sub-activity & In what way are we going to do it? \\
$\mathrm{R}$ & Why? & Goal & What goal do we want to achieve? \\
\hline
\end{tabular}




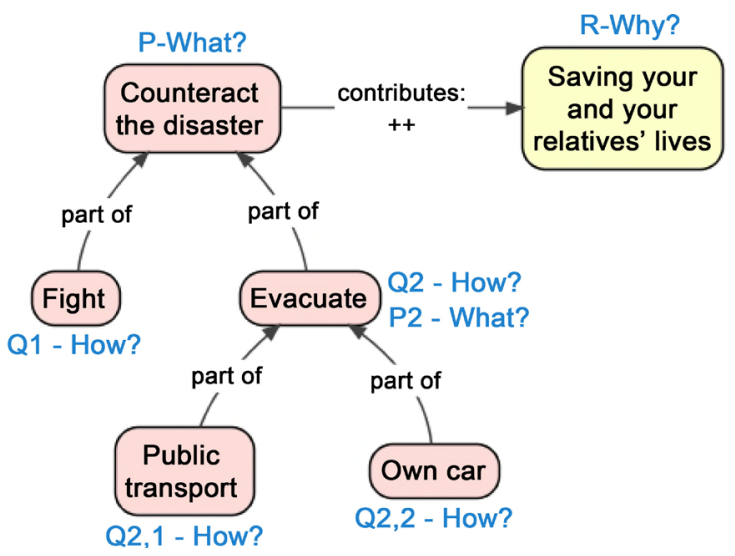

Figure 2. Counteracting a disaster.

activity can be subdivided into evacuation by car $(\mathrm{Q} 2,1)$ or by public transport $(\mathrm{Q} 2,2)$. Hence, the evacuation activity $(\mathrm{Q} 2)$ gets the status of a What activity (P2) for its constituents. The link between a How (Q) and a What (P) is established with the "part of" relation. Just like activities, goals can be decomposed into sub-goals as well.

Generalizing from the example in Figure 2: by applying the PQR formula recursively, we can model an experts' knowledge, that is, his behavioral patterns, at any desired level of detail. It should be noted that experts' knowing-how knowledge is to a certain extent tacit knowledge, which is internalized and cannot be described in every detail. Nevertheless, experts can convey part of their expertise by pinpointing good practices and pitfalls. By making this explicit, we can assess whether the know-how of experts, i.e., the way they achieve goals, cohere in order to make progress in a problematic situation together.

\subsection{Activities in Contexts}

A situation is comprised of several actors brought together to achieve goals. Rather than talking about actors, we prefer to model human behavior as roles. An actor is regarded as someone or something in the real world that can play one or more roles. It is also conceivable that a role is realized by more than one actor. With the concept of role we can abstract away from real world entities and make a situation more generally applicable.

Technically speaking, a situation and roles in a situation are both modeled with the unifying concept of context. The reason to unify these two concepts is that they are strongly related, or even stronger, they are actually the same when viewed from different perspectives. Take, for example, an organization, which can be seen as a role in particular situation together with other roles. But at the organization-level the organization can be regarded as a situation that can be decomposed on its turn into roles such as departments and individual employees.

The finer points of situations and roles are discussed with the help of the "Community resilience" example (Figure 3). A community tries to cope with disturbances (main activity-What) by minimizing the effect of disturbances (main goal-Why), including the more specific situation "Flooding" and two 


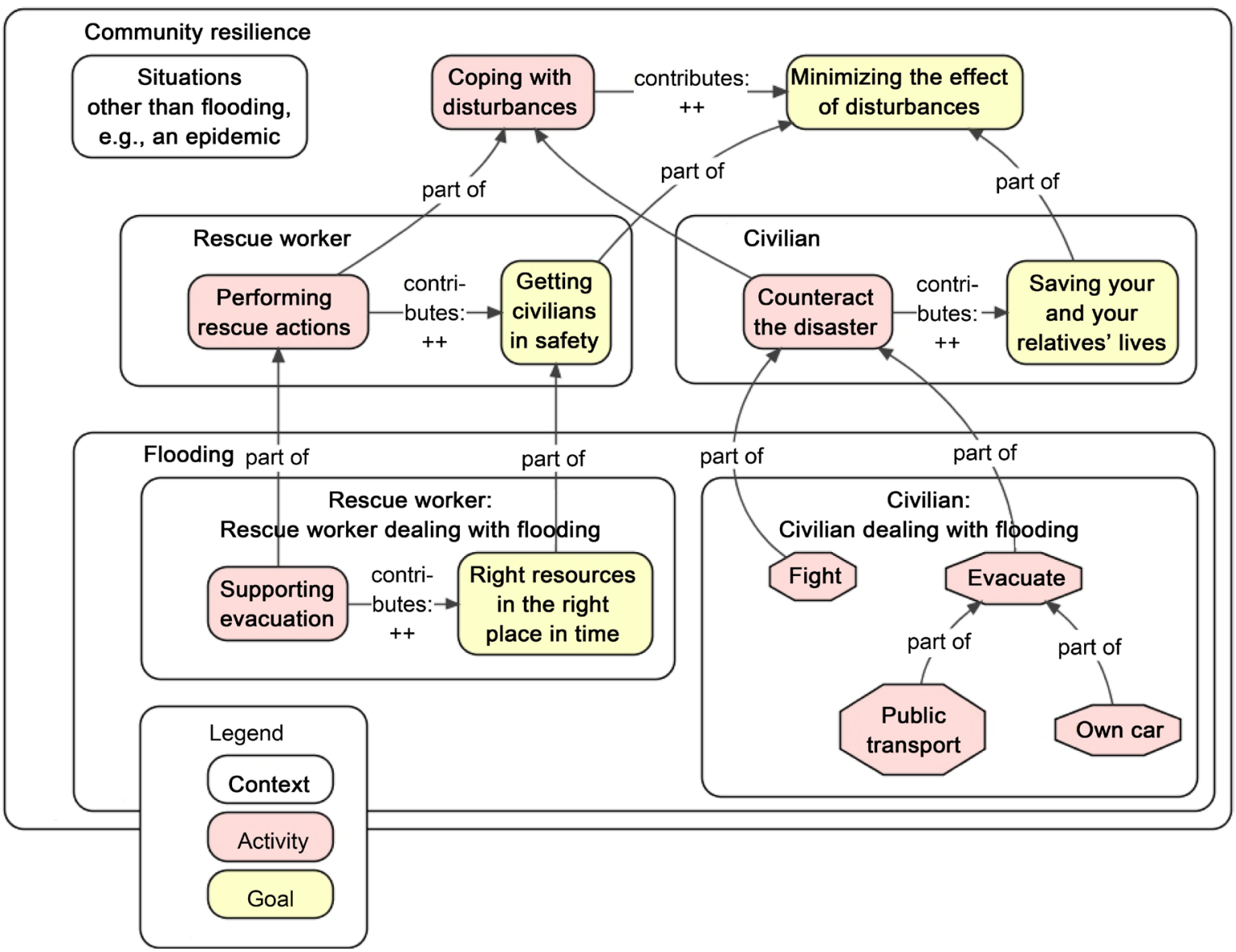

Figure 3. The situation "Community resilience" consisting of sub-contexts like "Flooding" (sub-situation) and "Civilian" (role).

roles namely "Rescue worker" and "Civilian".

Specific roles apply to specific situations. For example, the role "Civilian: Civilian dealing with flooding" shows that the role "Civilian dealing with flooding" is a sub-context of the situation "Flooding", as indicated by means of visually nesting contexts, and at the same time it is a sub-context of the role "Civilian", as established by the notation supercontext. sub-context. Thus, a sub-context can be part of than one super-context.

To conclude, it can be observed that a context is used to model situations comprising of sub-situations and roles. In turn, a role may be regarded as a situation for its constituents. That is, a role can be seen as a situation made up of sub-roles and sub-situations. By treating situations and roles similarly, refined and overlapping situations can be modeled matching reality in which situations and roles are not reducible to strict hierarchies.

\subsection{Interdependencies and Relations between Elements}

Roles played by actors in a situation are typically not island, they interact. The concept condition is used to characterize the quality of interactions between roles. They determine how and how well the actors in a situation interact and execute activities. Conditions can be influenced by the behavior of actors. They 
are often defined in a qualified way, e.g. "the availability of rescue workers", or "sufficient supply of evacuation resources". As a result, a condition can be regarded as an internal system indicator.

Typically, a goal and condition are related, expressed by the relation "contributes": a goal contributes to a condition. In Figure 4, the goal "Right resources in the right place in time" contributes positively to the condition "Evacuation resources". In other words, the condition is an indication of the extent to which the goal has been achieved. Note, a goal and a condition are deliberately modeled as different elements, because in real situations it frequently occurs that achieving one goal (contributing to a condition) can be undermined by achieving another goal (contributing to the same condition). Take for instance (not shown in the examples), a government formally informing civilians during a disturbance. The activities performed by civilians are likely to depend on the quality of information given by the government. This condition might be undermined though by civilians who spread rumors, whether deliberately or true or not, resulting in a lower information quality level. This might confuse civilians who have to decide who to trust, the government or the rumors.

The examples in Figure 4 and Figure 5 show the type and quality of relations between activities, goals and conditions:

- Dependency: an activity may depend on a condition, as is the case in Figure 4: evacuation with public transport "depends on" on the availability of evacuation resources. Dependency between an activity and a condition shows that the extent to which the activity can be executed depends on how well this activity is facilitated by other activities contributing positively to the condition the activity depends on (see Figure 5). It is meant as an efficacy relation, a necessary condition, which must be satisfied in order to perform an activity. That is, it is not possible to evacuate without even a minimal availability of evacuation resources.

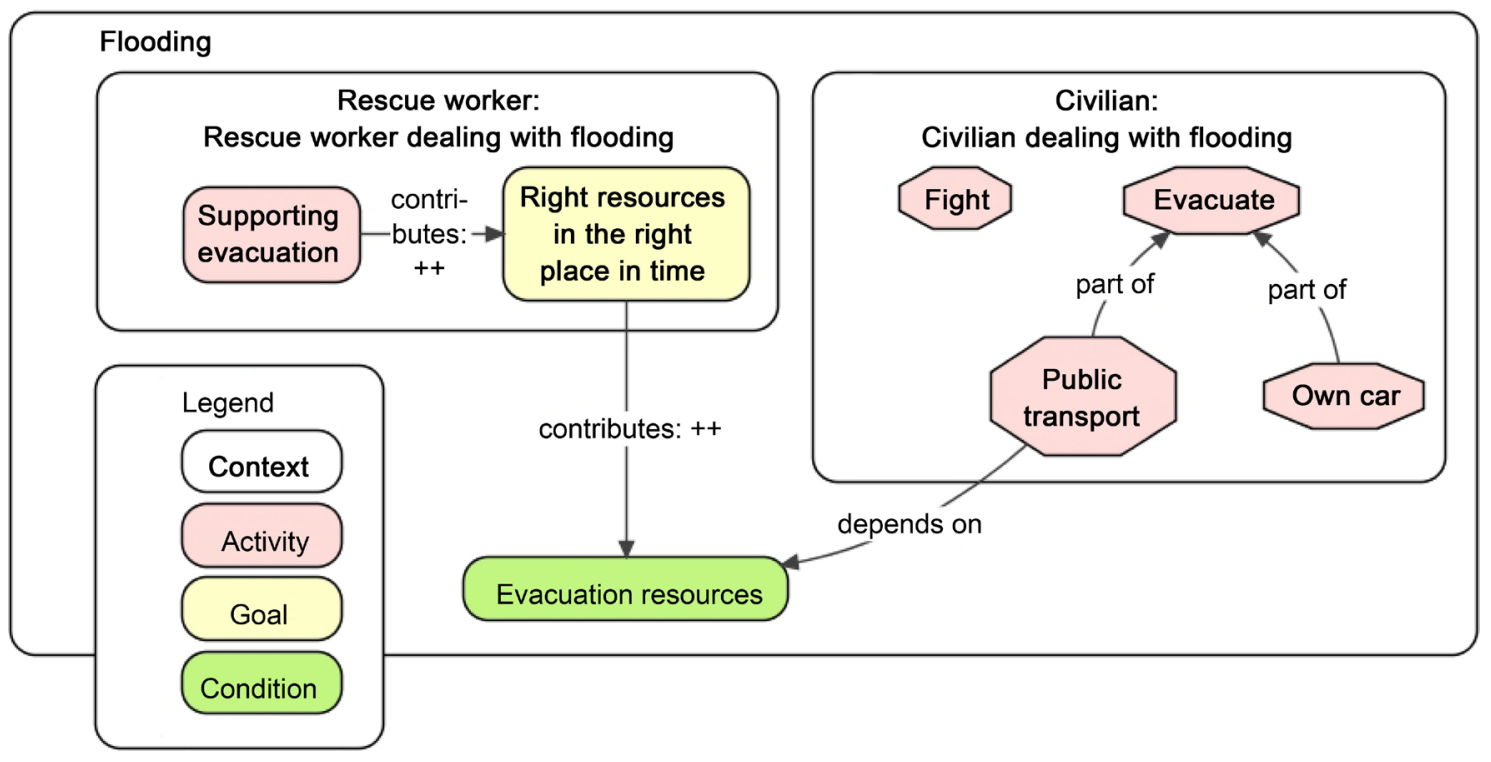

Figure 4. Goals contributing to conditions. 


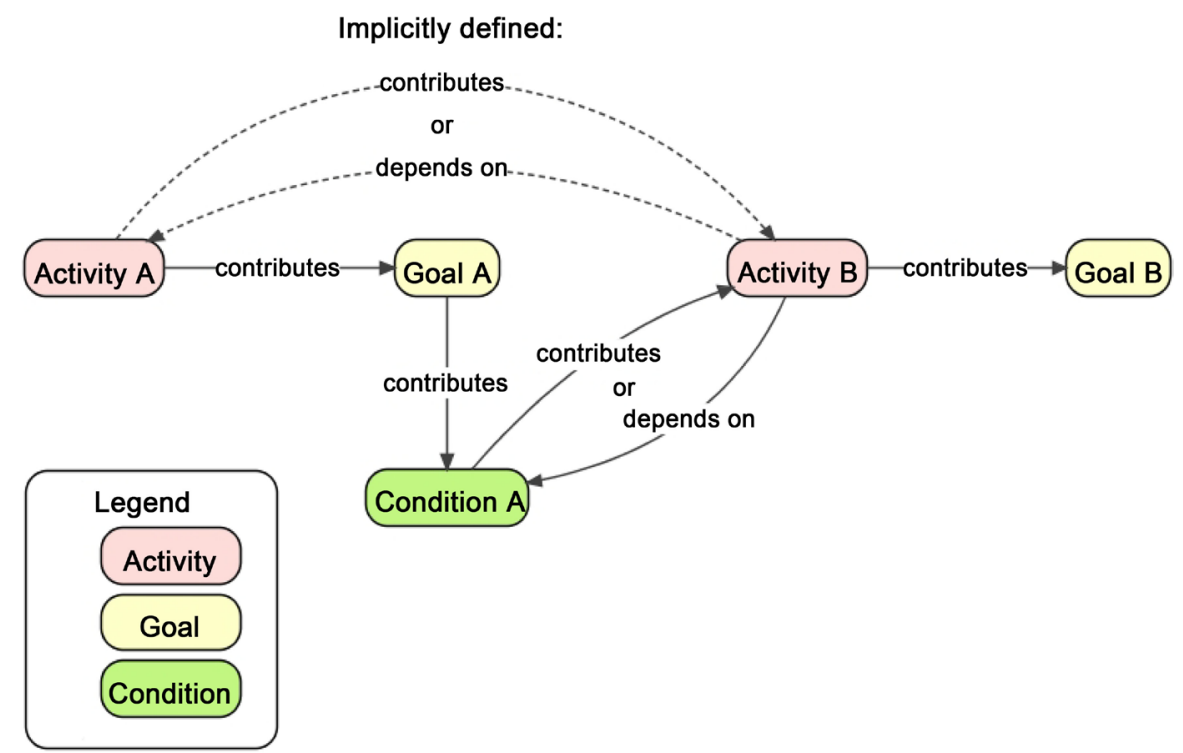

Figure 5. Interacting elements.

- Contribution: a goal contributes to a condition, including a range of values $(++,+,+/-,-,--)$, indicating a negative, neutral or positive contribution. The relation "contributes" is not as strong as the relation "depends on". A dependency can be expressed as "contributes" for modeling situations in which the relation between an activity and a condition is weaker.

The semantics of the "depends on" and the "contributes" relations have been deliberately not defined strictly. First, in our experience, these two relations are sufficient defined to get the finer points of interacting roles in a situation across. Second, precise definitions may actually restrict the applicability of the relations. As is the nature of the semantic web, ontologies may be refined to fit the application domain at hand.

Regarding the general pattern of relations as shown in Figure 5, the condition establishes an implicit relation between Activity A and Activity B. There is, however, no need to make the dotted relations between Activity A and B explicit, which have already been established by means of the "contributes" and "depends on" relations shown as solid lines.

\subsection{Worldviews of Actors Involved}

Regarding roles we have up to now focused only on one single way to carry out activities related to that role. However, people can carry out an activity in various ways. These different approaches originate from the variety people and their worldviews. And vice-versa, someone's worldview can vary depending on the situation he is engaged in. Therefore, different worldviews will have to be considered in modeling activities. A worldview is regarded in $\mathrm{EM}_{\text {ont }}$ as a particular way of role behavior in a given situation.

Worldviews can be included in the model similarly to the way contexts were used to model roles in specific situations. Figure 6 illustrates a situation with different worldviews: a Civilian can deal with flooding by leading the neighbor- 


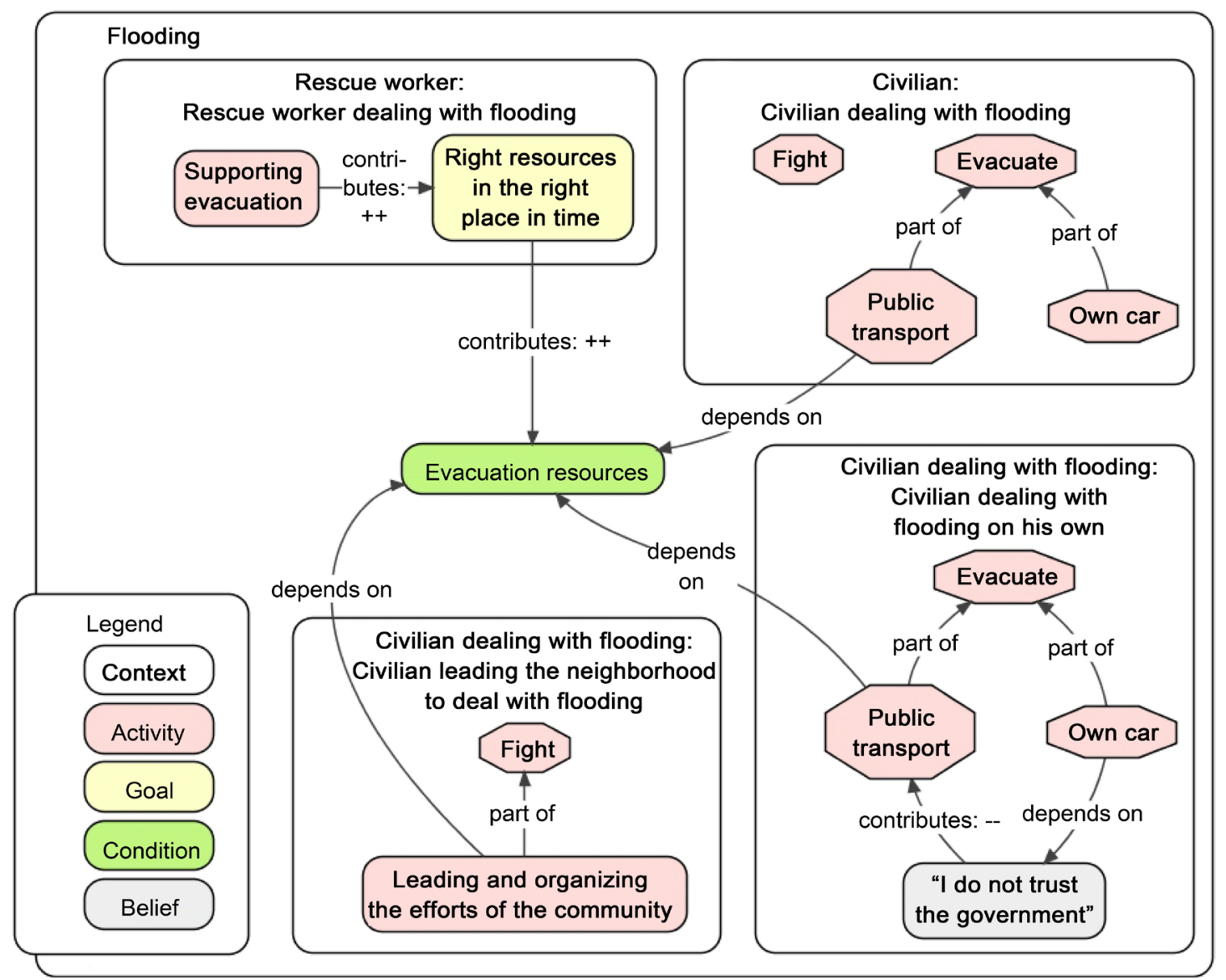

Figure 6. Worldviews and beliefs.

hood and helping his neighbors or by dealing with flooding on its own. The sub-situation "Civilian dealing with flooding on its own" includes the belief "I do not trust the government", which means that this particular civilian does not trust the government to organize public transport as evacuation means and will evacuate only with his own car.

\subsection{The Main Scheme of Community Resilience}

Concept maps show the relations between concepts as propositions visually. This is especially useful for conveying ideas between stakeholders. However, concept maps of complex situations tend to grow large. Creating clarity in a complex model, such as the one about community resilience (see Figure 7, composed from Figure 3 and Figure 6), can be done firstly by developing a main scheme presenting the big, more generic picture including only the most important situations (sub-contexts, or so-called "hooks"). Details of the different sub-contexts can be provided only when "zooming in", thus by developing separate schemes that describe the sub-context selected from the main scheme in more detail.

To the sub-contexts as shown in Figure 3, information can be added and removed, see Figure 6. For instance, specific roles at the bottom of the scheme such as "Civilian dealing with flooding on its own" and "Civilian leading the neighborhood to deal with flooding" are derived from the role "Civilian 


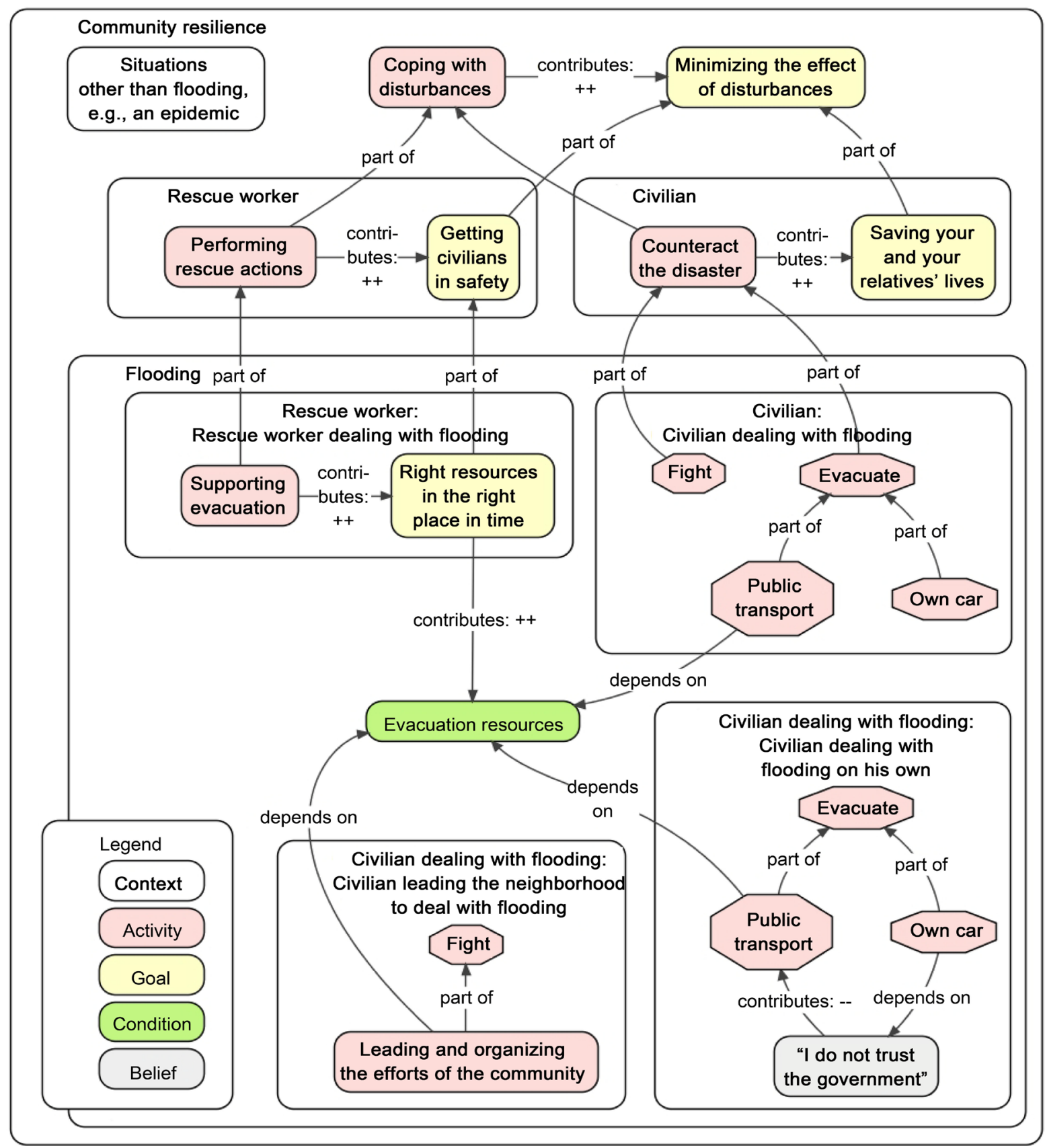

Figure 7. An overview of the situation Community resilience including the main contexts and other $\mathrm{EM}_{\text {ont }}$ modeling elements.

dealing with flooding". Modeling elements can be discarded when they are not of use or add value to a particular sub-context. For instance, the context "Civilian dealing with flooding on its own", the activity "Fight" has been removed. The octagonal shape of certain modeling elements indicates that this element occurs in other contexts as well. In Figure 4 and Figure 6 the activities "Fight" and "Evacuate" occur elsewhere in het context "Flooding" as well.

\subsection{Concluding Remarks}

The strength of modeling complex situations with $\mathrm{EM}_{\text {ont }}$ lies in putting patterns 
of (non-) human behavior, modeled with the PQR formula, in a context and applying these recursively. A context is key to modeling situations or roles, related activities and interactions of actors with different worldviews. The example of a flooding disaster is used as a simplified and incomplete illustration of a real situation. Real situations can be modeled in a comprehensive manner, but the models can also become very complex and big. Detailed descriptions of the sub-situations can be made by dividing a situation into sub-contexts and describing them in separate concept maps.

Subjects not discussed in this introduction to modeling with $\mathrm{EM}_{\text {ont }}$ include documenting good and bad practices, temporal orderings of (compound) activities and modeling conceptual knowledge and its connection to PQR's in a context. These subjects make modeling with $\mathrm{EM}_{\text {ont }}$ more comprehensive, yet does not imply introducing significant different elements to $\mathrm{EM}_{\text {ont }}$. They are discussed in the next, more formal section on the Expertise Management ontology.

\section{The Expertise Management Ontology}

$\mathrm{EM}_{\text {ont }}$ 's main purpose is to capture interacting (human) activity in particular situations, that is, knowing how (procedural) knowledge. In terms of the DIKW pyramid, $\mathrm{EM}_{\text {ont }}$ covers the knowledge and wisdom layer (see Figure 1). The main ontological categories and relations of $\mathrm{EM}_{\text {ont }}$ are shown in Figure 8.

The data and information layer of the DIKW pyramid is covered by the W3C standard Simple Knowledge Organization System (SKOS) [10]. Thesaurus-like information structures is constructed with SKOS thereby relating domain specific concepts in a meaningful way, that is, knowing-that knowledge. The application of SKOS is beyond the scope of this article, and is not discussed further.

\subsection{Intentional Elements}

Human activities, as well as other activities such as exhibited by for instance

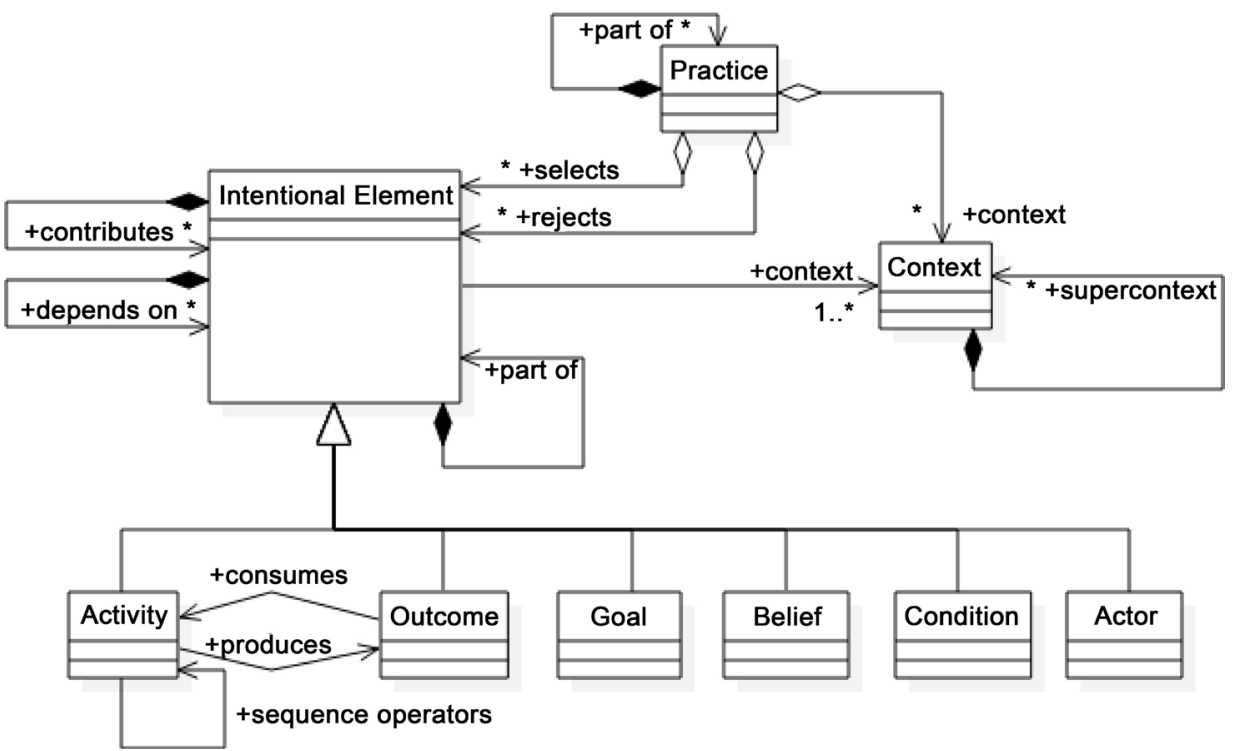

Figure 8. $\mathrm{EM}_{\text {ont }}$ 's main ontological categories and their relations. 
machines, are modeled with Intentional Elements (IE's) originating from the $\mathrm{PQR}$ formula. Key is that an activity (P - What) is executed in order to achieve a goal ( $\mathrm{R}$ - Goal) or to produce an outcome. The relation between an activity and a goal is "contributes", including a range of values $(++,+,+/-,-,--)$ to indicate a (strong) positive, a (strong) negative or a neutral contribution. The semantics of this relation are defined imprecise deliberately to pose no restriction to their application. As usual in ontology engineering, a property such as "contributes" can be refined to match the application at hand. The relations "produces" and "consumes" link an activity with an outcome in the sense that an activity produces or consumes an outcome. Activities, goals and outcomes and all the other IE's for that matter can be decomposed into sub-activities, sub-goals and sub-outcomes, respectively. The relation that establishes a hierarchy between IE's is the "part of" relation.

Since (compound) activities consist of sub-activities, there is a need to model temporal relations. The set of temporal relations has been derived from Use Case Maps [11]. See Table 3 for an overview.

IE's and their relations are expressed as propositions: subject $\stackrel{\text { predicate }}{\longrightarrow}$ object . For instance: Counteracting a disaster (subject, IE: activity) contributes to (predicate; relation) saving you and your relatives' lives (object, IE: goal). See paragraph 3.3 and Table 2 and Table 3 for a complete list of modeling elements and their relations.

\subsection{Contexts}

Human activity typically depends on the situation it occurs in. The ontological category Context is used to model situations and roles of actors played in a situation. As discussed in section 2.2, situations and roles are closely related, since a role can be viewed as a situation form a different perspective, as was shown by the example of organization. Taking the example of an organization again, it is conceivable that an organization plays a role in multiple situations. Therefore, a context may have multiple super-contexts resulting in a lattice-like context hierarchy. Just like IE's, contexts may be decomposed in sub-context by establishing "supercontext" relations between sub-contexts and contexts.

\subsection{Interaction}

Actors, and their activities organized as roles in a situation, are not isolated, they typically interact. An actor's activity depends on the behavior of other actors in the situation, or more generally: human activity depends on entities exhibiting behavior, as well as environmental constraints.

Two kinds of interactions between activities have been discussed already: produces/consumes and sync (see Table 3 ). These two relations are typically used to synchronize behavior between concurrent activities. Besides synchronization, interaction can also be seen as facilitation. That is, one activity depends on the goods or service provided by another activity. The quality of a good or a service is modeled as a condition. This interaction pattern has been described 
Table 2. $\mathrm{EM}_{\text {ont }}$ relations between modeling elements (subjects and objects).

\begin{tabular}{|c|c|c|c|c|c|c|c|c|}
\hline & \multicolumn{8}{|c|}{ Objects } \\
\hline & & Activity & Actor & Belief & Condition & Context & Goal & Outcome \\
\hline \multirow{7}{*}{ 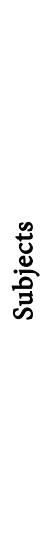 } & Activity (process) & $\begin{array}{l}\text { part of; temporal relations: } \\
\text { seq, par, join, sync, guard }\end{array}$ & depends on & depends on & $\begin{array}{l}\text { contributes; } \\
\text { depends on }\end{array}$ & & contributes & $\begin{array}{c}\text { consumes; } \\
\text { produces }\end{array}$ \\
\hline & Actor & contributes & part of & & & & & \\
\hline & $\begin{array}{c}\text { Belief } \\
\text { (pre-condition) }\end{array}$ & contributes & & part of & contributes & & & \\
\hline & Condition & contributes & & depends on & part of & & & part of \\
\hline & $\begin{array}{c}\text { Context } \\
\text { (situation, role) }\end{array}$ & & & & & supercontext & & \\
\hline & Goal & & & & contributes & & part of & \\
\hline & Outcome & $\begin{array}{l}\text { consumed by; } \\
\text { produced by }\end{array}$ & & & & & & part of \\
\hline
\end{tabular}

Table 3. Temporal $\mathrm{EM}_{\text {ont }}$ relations.

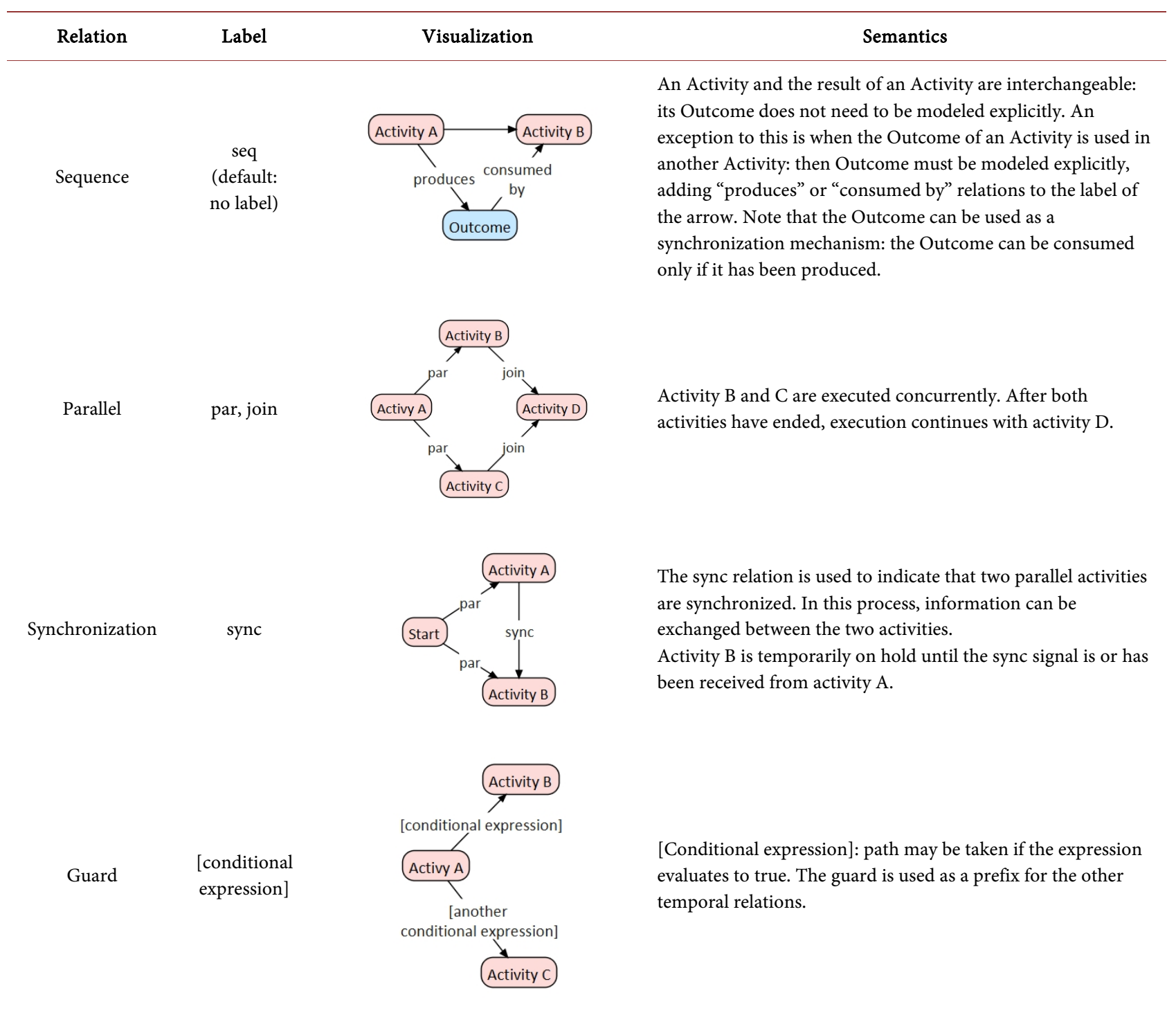


in Figure 5. By the same token, an activity may also depend on a belief or a pre-condition. The difference between a condition and a belief is that the former can be changed within the context (situation, system) whereas the latter cannot. Typical examples of a belief include fixed ideas and legislation.

\subsection{Practices}

Consider a situation made up by several roles all acting purposefully to achieve goals. According to the PQR formula and the MPF, activities performed by roles can be decomposed in What and How activities recursively. Alternative How's (Q's), for realizing a particular What $(\mathrm{P})$, introduce degrees of freedom. To reach a common goal, activities must be geared towards another. Effectively, this means that particular How's must be chosen in such a way that synergy is achieved. To put it differently, by choosing activities the degrees of freedom are reduced.

A good practice can be defined as choosing activities in such a way that activities cohere in the sense that (common) goals are reached effectively and efficiently. A bad practice, on the other hand, can be regarded as activities that cohere less optimally. The ontological category Practice provides a setting in which IE's are selected or rejected explicitly. A practice may be decomposed in sub-practices. In a sub-practice the degrees of freedom are further reduced. This reduction continues recursively until no degrees of freedom are left. In that case, a practice is called an experience because a progression of activities that actually have happened do not contain any degrees of freedom. $\mathrm{EM}_{\mathrm{ont}}$ uses experiences to capture case studies.

\section{Expertise Management Methodology}

The Expertise Management Methodology (EMM) is a broad applicable methodology to utilize each other's expertise to make progress in problematic situations. EMM is a methodology, not a method. It can be regarded as a framework based on systems thinking and action research. Like with Soft Systems Methodology (SSM), applicants are free to apply suitable methods and techniques for the problematic situation at hand, including quantitative methods. $\mathrm{EM}_{\text {ont }}$ is the foundation of EMM and is used to capture expertise in the form of human activity systems concisely and precisely.

EMM is rooted in systems thinking, especially soft systems thinking although there is also room for hard system approaches like System Dynamics - the fifth discipline [12]. However, unlike SSM, which can be regarded as an interpretive approach in which human actors or stakeholders construct their own interpretation of reality, EMM favors Critical Realism (CR) [13]. In contrast with SSM, CR assumes a systemic reality that exhibits causal relations between entities. $\mathrm{EM}_{\text {ont }}$ is used to make these causal relations between actors explicit. But at the same time, $\mathrm{CR}$ acknowledges that human actors give meaning to problematic situations, which corresponds to worldviews in soft systems thinking. CR and systems thinking are closely related as discussed in Systems Thinking, Critical Realism 
and Philosophy [14].

The concept of situation is central in EMM. A situation contains actors who perform activities to achieve goals. Usually it is possible to formulate a shared goal in an abstract sense. The way to achieve the goal might differ because of differences in worldviews and specific, individual concerns. For instance, in the community resilience domain, we strive for a resilient community populated by individuals willing and capable of helping each other in case of disturbances. An individual is part of the community and is supposed to support the community, and in return the community supports an individual. This situation is problematic in the sense that it is often not clear what is expected from each other, and some individuals are free riders, not willing to support the community at all but do rely on the services provided by the community. With EMM, a structured process is provided to address such problematic situations. Basically, the process steps of SSM are followed, but again EMM is a methodology in which the process can be adapted to one's own liking. SSM recognizes four steps, which are not necessarily performed in the given order:

1) Finding out, who is involved, what are the concerns?

2) Model building, constructing $\left(\mathrm{EM}_{\text {ont }}\right)$ models to explicate worldviews;

3) Discussing and debating, a structured discussion on how to accommodate worldviews and to find arguably desirable and culturally feasible improvements;

4) Taking action, implementing changes.

In our experience, human actors and stakeholders find it difficult to share ideas about abstract issues such as community resilience in general. Therefore, the starting point for investigation is always a concrete problematic situation. This is what we call a case study. A case study is explored in line with the SSM steps discussed above. By means of abduction [15], a generalized $\mathrm{EM}_{\text {ont }}$ model is devised that explains the phenomenon in the case study best. Typically, the model will not give all the answers, that is, there are blank spots and assumptions. These are taken as a direction to further explore problematic situations by means of additional case studies typically resulting in a refined and adapted $\mathrm{EM}_{\text {ont }}$ model.

Abduction can be regarded as a mixture of induction and deduction, but less strict and more geared towards innovations. This befits Expertise Management where we explore new ways to utilize actors' expertise to make progress in wicked problems. Abduction is a cyclic process in which a Body of Knowledge and Skills (BoKS) is constructed and refined systematically. The constructed BoKS is defined in terms of $\mathrm{EM}_{\text {ont }}$.

\section{Implementation of the Body of Knowledge \& Skills}

$\mathrm{EM}_{\text {ont }}$ has been implemented in Semantic MediaWiki (SMW) [16] to publish BoKS on the web. According to the SMW website [17]: "Semantic MediaWiki is a free, open-source extension to MediaWiki-the wiki software that powers Wikipedia-that lets you store and query data within the wiki's pages. Semantic 
MediaWiki is also a full-fledged framework, in conjunction with many spinoff extensions that can turn a wiki into a powerful and flexible knowledge management system. All data created within SMW can easily be published via the Semantic Web, allowing other systems to use this data seamlessly."

In our experience, SMW is one of the most flexible platforms for structuring knowledge. SMW supports the fundamental semantic web proposition: subject $\stackrel{\text { predicate }}{\longrightarrow}$ object , albeit in a slightly different form. A wiki page takes the role of subject. It contains zero or more predicates, which are called properties, to relate to objects. An object may be another wiki page or a value, such as a number, date, string or coordinate. The data can be queried with a simple, but restricted query language. A triple store can be attached to SMW turning the wiki into an endpoint that can be queried from the outside or within the wiki itself using SPARQL. It must be noted, however, that SPARQL support is not fully realized yet in SMW.

A semantic wiki can be regarded as an ordinary wiki, such as Wikipedia, and a semantic database in one. This is powerful combination because the formality implied by an ontology is balanced against the free format of a wiki page. Ontological elements, such as activities and contexts (situations and roles), can be described textually augmented with pictures and references to relevant resources. In addition, a semantic wiki can be turned into a website comprised of a number of wiki pages. The navigation structure of the (wiki) website is derived automatically from the $\mathrm{EM}_{\text {ont }}$ semantic relations. By changing semantic relations, the navigation structure is changed accordingly. Therefore, the (wiki) website is always consistently up to date.

Besides using the semantic relations for navigation purposes, concept maps can also be used to navigate. A concept map can be turned in a clickable image in a wiki page. By clicking on a concept, the user is lead to a corresponding page in which the concept, such as a context or activity, is discussed. Usually, we simplify the concept maps and make them more graphic-oriented in order to not overwhelm the user.

It is relatively easy to replace the standard look \& feel of SMW, the so-called vector skin (Wikipedia look), with a tailor made skin. See Figure 9 as an example. It shows the portal of an expertise management system (wiki) about coastal protection (hoogwaterbescherming in Dutch).

\section{Related Work}

The notion of hierarchically organized human activity systems, i.e. worldviews,

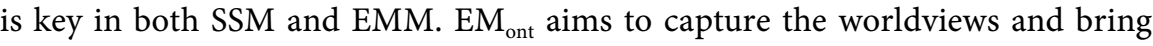
them together to determine how to achieve shared goals. In addition, $\mathrm{EM}_{\text {ont }}$ supports a flexible approach to model situations and roles with help of the unifying concept of context. To our knowledge, no ontology has been published with similar characteristics. However, closely related to SSM and EMM are Activity Theory and Process Ontology.

In Activity Theory [18] a systemic perspective is taken to model the mental 


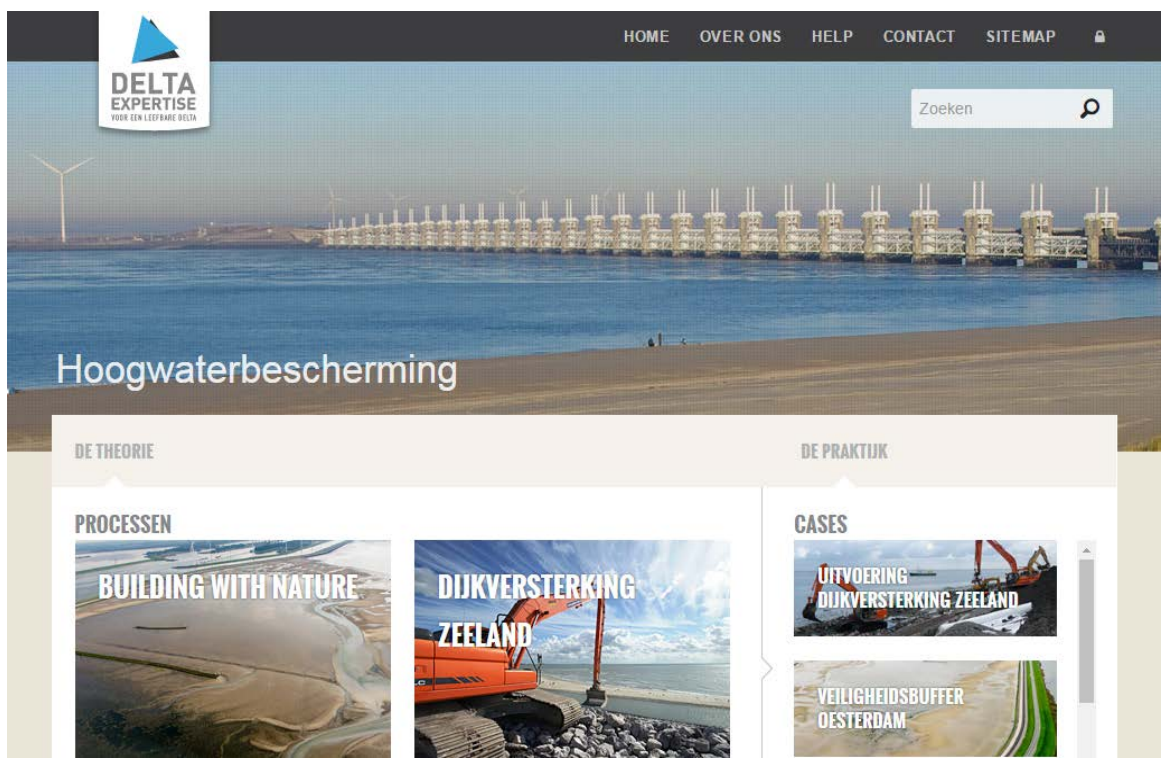

Figure 9. Tailor made skin used for the wiki about coastal protection, 'hoogwaterbescherming' in Dutch (screenshot).

capabilities of a single individual in relation to its environment by taking cultural and technical aspects into account. Activity Theory is amongst others applied in the human-computer interaction domain [19]. More recently, Activity Theory is also applied to human activity recognition, especially in the domain of ambient assisted living in which technology innovations assist disabled persons in their daily activities (see [20] for a survey). OntoSOC: Sociocultural Knowledge Ontology is an example of Activity Theory applied in the social domain [21]. Activity Theory recognizes that individuals have poly-motivations and that they are part of a community in which they play a role which is governed by rules. However, the notion of several human activity systems in one model, as in $\mathrm{EM}_{\text {ont }}$ is not explicitly present in Activity Theory models.

Process Ontology can be understood from two angles. In the philosophical sense, a Process Ontology is concerned with the dynamics of being as becoming [22]. As such, a Process Ontology has a wider scope than the traditional substance ontology approach, in addressing issues as the role of the mind in our experience of reality as becoming. This is a similar move that has been taken by Critical Realism that assumes a systemic reality and at the same time, individuals give their own meaning to phenomenon in reality. This is precisely what is done with $\mathrm{EM}_{\text {ont }}$ for Expertise Management: bringing together multiple viewpoints from experts in the form of human activity systems to act purposefully together in problematic situations. In computer science, Process Ontology refers to ontologies describing processes with ontological categories such as processes, activities, goals, roles and actors [23]. The focus of Process Ontology is mainly to describe business processes, planning and workflows. For this purpose, process ontologies offer more precise modeling concepts than $\mathrm{EM}_{\text {ont }}$, including subtle temporal orderings between activities, such as overlapping activities. $\mathrm{EM}_{\text {ont }}$ could benefit from these richer set of modeling elements. However, the need for a 
richer set is hardly felt in practice, because the notion of multiple human activity systems in the area of Expertise Management is considered more important than precise temporal orderings of activities. The notion of multiple human activity systems in Process Ontologies is not as infused as in $\mathrm{EM}_{\text {ont }}$. Usually, a role category serves the purpose of identifying role behavior, albeit in a limited way in the sense of organizational purposes rather than seeking ways to act purposefully together as in $\mathrm{EM}_{\text {ont }}$.

\section{Looking Back and Ahead}

Expertise Management Methodology and Expertise Management ontology have been applied in diverse domains in the past four years. Not long after its conception, the ontology settled in its definite form and has not been changed since. This has strengthened our confidence that the ontology is fit to capture human activity in complex situations.

Human activity is described in terms of patterns. The patterns are found by applying the systematic process of EMM. In essence, EMM is a group learning process. The process of learning develops by dialogs involving experts who give meaning to particular situations. Further exploration about processes, like collaboration and co-creation with the help of $\mathrm{EM}_{\text {ont }}$, to "collectively do the right things" is desired. Good and bad practices of group learning processes, its facilitation, and moral and ethical aspects require further investigation. The research center EVM has started this process by learning and carrying out action research in living labs. Furthermore, since $\mathrm{EM}_{\text {ont }}$ is based on the Memory-Prediction Framework, it is interesting to explore whether the group learning process can be supported by machine learning.

\section{References}

[1] Churchman, C.W. (1968) The Systems Approach. Delacorte Press, New York.

[2] Checkland, P. and Poulter, J. (2006) Learning for Action: A Short Definitive Account of Soft Systems Methodology and Its Use for Practitioners, Teachers and Students. Wiley, Hoboken.

[3] Wilson, B. and Van Haperen, K. (2015) Soft Systems Thinking, Methodology and the Management of Change. Palgrave, Basingstoke.

[4] Gettier, E.L. (1963) Is Justified True Belief Knowledge? Analysis, 23, 121-123. https://doi.org/10.1093/analys/23.6.121

[5] Abbas, J. (2010) Structures for Organizing Knowledge: Exploring Taxonomies, Ontologies, and Other Schemas. Neal-Schuman Publishers, Inc., Chicago.

[6] Hawkins, J. (2004) On Intelligence. Times Books, New York.

[7] Kurzweil, R. (2012) How to Create a Mind: The Secret of Human Thought Revealed. Viking Adult, New York.

[8] Mountcastle, V.B. (1957) Modality and Topographic Properties of Single Neurons of Cat's Somatic Sensory Cortex, Modality and Journal of Neurophysiology, 20, 408-434.

[9] Lam, A. (2000) Tacit Knowledge, Organizational Learning and Societal Institutions: An Integrated Framework. Organization Studies, 21, 487-451. https://doi.org/10.1177/0170840600213001 
[10] W3C (2012) SKOS Simple Knowledge Organization System-Home Page. https://www.w3.org/2004/02/skos/

[11] International Telecommunication Union (2008) User Requirement Definition (URN)-Language Definition. ITU, Geneva.

[12] Senge, P. (1990) The Fifth Discipline: The Art and Practice of the Learning Organization. Random House, London.

[13] Bhaskar, R. (1989) Reclaiming Reality: A Critical Introduction to Contemporary Philosophy. Verso, London.

[14] Mingers, J. (2015) Systems Thinking, Critical Realism and Philosophy: A Confluence of Ideas (Ontological Explorations). Routledge, Abingdon-on-Thames.

[15] Magnani, L. (2001) Abduction, Reason, and Science: Processes of Discovery and Explanation. Kluwer Academic Plenum Publishers, New York. https://doi.org/10.1007/978-1-4419-8562-0

[16] Koren, Y. (2014) Working with MediaWiki. 2nd Edition, WikiWorks Press, New York.

[17] SMW (2016) Semantic MediaWiki. https://www.semantic-mediawiki.org/wiki/Semantic_MediaWiki

[18] Engeström, Y., Miettinen, R. and Punamäki, R.L. (1999) Perspectives on Activity Theory. Cambridge University Press, Cambridge. https://doi.org/10.1017/CBO9780511812774

[19] Kaptelinin, V. and Nardi, B. (2012) Activity Theory in HCI: Fundamentals and Reflections, Morgan \& Claypool, San Rafael.

[20] Rodríguez, D., Cuéllar, M.P., Lilius, J. and Calvo-Flores, M.D. (2014) A Survey on Ontologies for Human Behavior Recognition. ACM Computing Surveys, 46, Article No. 43.

[21] Kaladzavi, G., Diallo, P.F., Kolyang and Lo, M. (2015) OntoSOC: Sociocultural Knowledge Ontology. International Journal of Web \& Semantic Technology, 6, 1-8. https://doi.org/10.5121/ijwest.2015.6201

[22] Rescher, N. (2012) Stanford Encyclopedia of Philosophy: Process Philosophy. https://plato.stanford.edu/entries/process-philosophy/

[23] Gangemi, A., Borgo, S., Catenacci, C. and Lehman, J. (2005) Task Taxonomies for Knowledge Content. Laboratory for Applied Ontology (LOA), Trento.

Scientific Research Publishing

Submit or recommend next manuscript to SCIRP and we will provide best service for you:

Accepting pre-submission inquiries through Email, Facebook, LinkedIn, Twitter, etc.

A wide selection of journals (inclusive of 9 subjects, more than 200 journals)

Providing 24-hour high-quality service

User-friendly online submission system

Fair and swift peer-review system

Efficient typesetting and proofreading procedure

Display of the result of downloads and visits, as well as the number of cited articles

Maximum dissemination of your research work

Submit your manuscript at: http://papersubmission.scirp.org/

Orcontact jcc@scirp.org 